\title{
The costs of breast cancer in a Mexican public health institution
}

\author{
Jacobo Alejandro Gómez- \\ Rico' \\ Marina Altagracia-Martínez ${ }^{\prime}$ \\ Jaime Kravzov-Jinich' \\ Rosario Cárdenas-Elizalde \\ Consuelo Rubio-Poo ${ }^{2}$ \\ 'Universidad Autónoma \\ Metropolitano-Xochimilco (UAM-X), \\ Departments: Biological Systems \\ and Healthcare, Biological and \\ Health Sciences Division (DCBS); \\ ${ }^{2}$ Universidad Nacional Autónoma \\ de México (UNAM), Faculty \\ of Professional Studies-Zaragoza \\ (FES-Zaragoza)
}

\begin{abstract}
Breast cancer (BC) is the second leading cause of death as a result of neoplasia in Mexico. This study aimed to identify the direct and indirect costs of treating female outpatients diagnosed with $\mathrm{BC}$ at a Mexican public hospital. A cross-sectional, observational, analytical study was conducted. A total of 506 medical records were analyzed and 102 were included in the cost analysis. The micro-costing process was used to estimate treatment costs. A 17-item questionnaire was used to obtain information on direct and indirect costs. Of the 102 women with BC included in the study, $92.2 \%$ (94) were at Stage II, and only $7.8 \%$ at Stage I. Total direct costs over six months for the 82 women who had modified radical mastectomy (MRM) surgury were US\$733,821.15. Total direct costs for the 15 patients with conservative surgery (CS) were US\$138,190.39. We found that the total economic burden in the study population was much higher for patients with MRM than for patients with CS.
\end{abstract}

Keywords: breast cancer, Mexican women, direct and indirect costs

\section{Introduction}

Breast cancer (BC) is the most common malignancy in women and comprises $18 \%$ of all female cancers. ${ }^{1}$ BC remains a public-health issue on a global scale, accounting for one million new cases worldwide each year. ${ }^{1,2}$ The two variables most strongly associated with the incidence of $\mathrm{BC}$ are age and gender., ${ }^{1,3}$

$\mathrm{BC}$ poses a challenge to public health in Mexico, as the second leading cause of death due to cancer in women older than 25 years, second only to cervical cancer. ${ }^{4}$ $\mathrm{BC}$ has the highest mortality rates in women of reproductive age; the mean age of death from this cause of death is 56 . BC is second only to diabetes as a cause of death in women aged 45 to $55.5^{5}$ Morbidity due to BC is increasing every year in Mexico. It is estimated that by 2010 the mortality rate as a result of $\mathrm{BC}$ in adult women will be 13 per 100,000, and will account for 4500 deaths annually in Mexico. ${ }^{6}$

In developed countries, $50 \%$ of $\mathrm{BCs}$ in women are detected at stages I or II. In Mexico, as in other countries in a similar stage of development, detection tends to be delayed. ${ }^{7}$ The latest report from the Mexican Ministry of Health states that $50 \%$ of newly detected cases of BC are at advanced stages (III or IV). ${ }^{7}$

Long-term survival rates for many types of cancer have improved substantially in recent decades because of advances in early detection and treatment. ${ }^{8}$ Therapeutic options for a given patient depend on several different factors including age, menopausal status, general health, tumor location, tumor cell type, and breast size. The most important factor is the stage of the cancer. ${ }^{9}$ Breast-conserving surgery plus adjuvant chemotherapy, or radical mastectomy plus chemotherapy, are the options usually considered (although this choice is not without controversy). ${ }^{10}$ A variety of treatments are available for BC, which differ in safety, efficacy, and cost. Rational allocation of resources is necessary if the increasing demand for 
health care services is to be met. This is especially true for public healthcare institutions.

The burden of a specific disease is frequently estimated using cost of illness (COI) and/or cost-effectiveness studies, especially in developed countries. ${ }^{11-20}$ Nevertheless, COI studies have been criticized because they do not provide information on the effectiveness of spending. ${ }^{20,21}$ Some authors support the usefulness of COI because these studies highlight the magnitude of the effect of an illness on society or a part of society. ${ }^{22}$

In Mexico (a middle-income country), these effects are significant because $\mathrm{BC}$ and other chronic diseases are on the rise, and spending on services for their treatment competes in a context of scarce economic information for decision-making and an increasing need to prioritize resources. Knowledge of the cost of an illness can help policy makers to decide which diseases need to be addressed first by health care and prevention policy. Furthermore, these studies can indicate which cures would be most valuable in reducing the burden of disease. For example, COI can show the federal government what financial impact a disease has on programs such as public health care systems and institutions, thus providing important information for cost-effectiveness analyses. ${ }^{23}$

$\mathrm{COI}$ and cost-effectiveness studies are, however, scarce in Mexico. To date, it is unclear how far the costs, risks, and efficacy of BC interventions might outweigh those of other investments in health care.

The objective of the present study was to identify the costs (direct and indirect) involved in treating female outpatients diagnosed with $\mathrm{BC}$ at the outpatient service department of La Raza Hospital, a Mexican Social Security Institute (IMSS) hospital.

\section{Material and methods}

The study was set in the Mexican public health care system. It was based at the Specialized Gyno-Obstetric Medical Unit (UMAE) No. 3 at La Raza IMSS National Medical Center in Mexico City. The study period was September 1, 2007 to November 30, 2007. The subjects were women aged 35 to 65 diagnosed with stage I or II BC, who had a clinical record prior to the study and who were receiving adjuvant chemotherapy after conservative surgery (CS) or radical mastectomy (RM).

\section{Inclusion criteria}

All women 35 or older with TNM Classification of Malignant Tumors (TNM) stage I or II BC who had had conservative or radical surgery; all women with a clinical record prior to the study. In Mexico, very few women under 35 years old are diagnosed with BC.

\section{Exclusion and elimination criteria}

These criteria included women with stage I or II BC and another cancer, pregnant women, women with $\mathrm{BC}$ at higher stages, and women who failed to attend scheduled medical appointments, were hospitalized, and/or who had received intensive or emergency treatment during the study period.

The study was population-based, cross-sectional, observational, and analytic. All clinical records of women with BC (506) who attended the outpatient unit at the study site during the study period were analyzed and divided into two groups according to the inclusion criteria. Group I consisted of 18 women at stage I or II BC who had had conservative surgery (CS) and who were being treated with adjuvant chemotherapy, radiotherapy, and/or hormone therapy. Group II consisted of 84 women with $\mathrm{BC}$ who had had radical surgery and who were receiving any of the same adjuvant treatments. The study was approved by La Raza Hospital Research Board and Ethics Committee. A fixed period of 6 months was used, based on the length of treatment (adjuvant chemotherapy).

The micro-costing process was used. ${ }^{24}$ A 17 -item questionnaire was applied to each woman in the study sample (102 subjects). Written consent was obtained from all participants before administration of the questionnaire, which was designed to identify the resources consumed by each woman, and the person (usually a relative) accompanying her. The questionnaire included questions about patient age; type of work and workplace; workdays lost due to the illness and medical appointments; level and type of education; marital status; distance from hospital and travel time to hospital; waiting time at the hospital for the appointment and during the drug treatment; whether the patient was accompanied and relationship to the accompanying person if present; and the cost of meals purchased outside the home while attending medical appointments or treatment. The cost of waiting time in the hospital was calculated from the number of days the patient and accompanying person were absent from work.

Direct medical costs were measured, that is, laboratory tests, physician and nurse salaries, and drugs (information on drug treatments was obtained from patient clinical records). Unit prices for medication were based on the official published 2007 prices. ${ }^{25}$ Unit prices of human resources costs (salaries) and BC interventions were provided by the hospital's Planning and Finance Department. The average cost of medical equipment used (based on a 10-year depreciation) was calculated similarly. Hospital overhead costs 
were calculated using administrative, cleaning, security, maintenance expenses, and the cost of consumables and general services associated with care given to women with BC. Transport costs for the patient and her accompanying person were measured (non direct medical costs).

Some assumptions were made: one US dollar was considered equivalent to 10.40 Mexican pesos (2007). Minimum and maxiumum average values were estimated for income loss due to illness, medical appointments, treatment, and food. For women and accompanying persons who were housewives or not employed outside the home, the minimum wage for Mexico City in 2007 (US\$147.82 monthly) was assumed.

Current cost was calculated assuming a discount rate of $5 \%$ per annum and 5 years of BC survival. No adjustment per year was done as any further chemotherapy treatment or surgery would be performed for women included in the present investigation. Only the minimum and maximum present costs were considered.

\section{Results}

The clinical files of 506 women were examined, but only 102 met the inclusion criteria. Only 102 patients were at stages I or II and were 35 years or older. Table 1 shows the characteristics of the 102 women included in the study: $43.1 \%$ (34) were aged 56 to $64 ; 34.4 \%$ (32) were aged 45 to $55 ; 92.2 \%$ (94) were at stages IIA or IIB and only 7.8\% (8) were at stage I. $82.4 \%$ (84) received modified radical mastectomy (MRM) and $17.6 \%$ (18) received conservative surgery (CS).

Medical records showed that $80.4 \%$ (82) of the women in the study were treated with fluorouracil, epirubicin, cyclophosphamide (FEC), 14.6\% (15) with cyclophosphamide, methotrexate, fluorouracil (CMF), and 4.9\% (5) with other treatment combinations.

The results of the questionnaire applied to the 102 women included in the study are summarized in Table 1 . The majority $(57.9 \%)$ of women had only completed elementary education; $23.5 \%$ (24) had completed ninth grade; and 14.7\% (24) had completed technical or vocational training; $73.4 \%$ (75) of the women were not employed outside the home; $23.7 \%$ (24) were employed, and $2.9 \%$ (3) were self-employed.

Table 1 also shows data on accompanying persons and travel time to the hospital. Patients were accompanied by a son or daughter in $36.2 \%$ (37) of cases, and by a spouse in $30.4 \%$ (31) of the cases; $80.39 \%$ (82) of accompanying persons were not employed outside the home. Travel time to the hospital was 91 to 120 minutes for $39.21 \%$ (40) of the women, and less than 60 minutes for $36.27 \%$ (37).
Table 2 shows the information gained from the questionnaire on expenses (time and money). These data were used to calculate direct and indirect nonmedical costs related to expenses incurred by the patients.

Because $60.77 \%$ of subjects spent less than US $\$ 4.80$ per hospital visit, the average transport cost of US $\$ 4.80$ per visit was estimated (Table 2). Table 2 also shows that $88.23 \%$ (90) of the women in the study said that they spent 4 to 6 hours at the hospital; 73.4\% (75) of the women were housewives, and applying the minimum wage yielded a cost of US\$2.43. As shown in Table 2, seven patients (6.87\%) spent less than US\$4.80 on meals during hospital visits, for which an average value of US\$4.32 is assumed; 11 patients $(10.78 \%)$ spent between US\$4.80 and US\$9.60, and an average of US\$5.28 is assumed for this group. For the calculation of loss of income (indirect costs) due to illness, only $19(18.63 \%)$ patients reported lost income (Table 2), at an average amount of US\$144.24 per month for 6 months of treatment. The cost of dietary change was estimated to be US\$115.38 per month (Table 2).

For medical expenses not covered by the social security system, the average was US\$81.25 for the $19.6 \%$ (20) of patients who reported these expenses (Table 2). Other medical expenses due to the illness were reported by 56 patients (60.70\%); the average cost for this group was US\$96.49 per month (Table 2).

Table 3 shows the results of nonmedical direct and indirect costs grouped and calculated for the total sample (102 women), taking into consideration 6 visits per woman, 6 months of treatment, and the number of patients who responded to each item in the questionnaire.

The total cost for transport was US\$2,942.30 for the 102 women included in the study (Table 3 ). The cost of meals for these 18 patients over 6 months of treatment was thus calculated as US\$9553.84 (Table 3). Total cost of dietary change was US\$70, 615.38 (Table 3). Total noncovered medical cost is reported as US\$487.50 (Table 3). Other nonmedical expenses due to the illness were reported by 56 patients $(64.70 \%)$; the average cost for this group over 6 months of treatment was US\$5,235.57 (Table 3).

Total direct nonmedical costs were US\$88,834.61. Total indirect costs of time at hospital were US\$1312.61-US\$1961.13 and loss of income due to illness was US\$16,442.30 (Table 3). Minimum and maximum total costs are shown in Table 3.

Table 4 shows that the costs for medical treatment and the cost per treatment cycle per patient was US\$1140.38 for FEC and US\$1207.31 for CMF. The total cost for six treatment cycles was US\$71,160.00 for FEC and 
Table I Sociodemographic variables, type of surgery and chemotherapy data from questionnaire applied to I02 women with breast cancer

\begin{tabular}{|c|c|c|c|}
\hline & Value & Number of patients & $\%$ \\
\hline \multirow[t]{3}{*}{ Age } & $35-45$ & 26 & 25.5 \\
\hline & $46-55$ & 32 & 31.4 \\
\hline & $56-65$ & 34 & 43.1 \\
\hline \multirow[t]{3}{*}{ Stage } & I & 8 & 7.8 \\
\hline & IIA & 47 & 46.1 \\
\hline & IIB & 47 & 46.1 \\
\hline \multirow[t]{2}{*}{ Type of surgery } & Conservative & 18 & 17.6 \\
\hline & MRM & 84 & 82.4 \\
\hline \multirow[t]{3}{*}{ Chemotherapy } & CMF & 15 & 14.6 \\
\hline & FEC & 82 & 80.4 \\
\hline & Other & 5 & 4.9 \\
\hline \multirow[t]{5}{*}{ Level of education } & None & 2 & 2 \\
\hline & Elementary & 59 & 57.9 \\
\hline & 9th grade & 24 & 23.5 \\
\hline & Technical/vocational & 15 & 14.7 \\
\hline & Post-secondary & 2 & 2 \\
\hline \multirow[t]{3}{*}{ Occupation } & Homewife & 75 & 73.4 \\
\hline & Employed & 24 & 23.7 \\
\hline & Self-employed & 3 & 2.9 \\
\hline \multirow[t]{5}{*}{ Accompanying person } & Spouse & 31 & 30.40 \\
\hline & Son or daughter & 37 & 36.27 \\
\hline & Brother or sister & 14 & 13.72 \\
\hline & Friend & 15 & 14.70 \\
\hline & Other & 5 & 4.91 \\
\hline \multirow[t]{3}{*}{ Occupation of accompanying person } & Housekeeper & 82 & 80.39 \\
\hline & Employed & 18 & 17.64 \\
\hline & Self-employed & 2 & 1.97 \\
\hline \multirow[t]{4}{*}{ Travel time to hospital } & $<60$ minutes & 37 & 36.27 \\
\hline & $61-90$ minutes & 17 & 16.67 \\
\hline & $91-120$ minutes & 40 & 39.21 \\
\hline & $>120$ minutes & 8 & 7.85 \\
\hline
\end{tabular}

Abbreviations: CMF, cyclophosphamide, methotrexate, fluorouracil; FEC, fluorouracil, epirubicin, cyclophosphamide; MRM, modified radical mastectomy.

US\$7,783.85 for CMF. Data on treatments were obtained from the patient clinical records.

Table 4 shows the total sums of direct (medical and nonmedical) and indirect costs calculated for the average treatment period of 6 months for all patients. Only 97 of the 102 women received FEC or CMF; the other five women received other treatment combinations. Because of the high variability in cost of the other treatments, these five patients are not included in the sum.

Total direct costs for women with MRM were US\$733,821.15, and for women with CS were US\$138,190.38 (Table 4). Total indirect costs ranged from a minimum of US\$17,737.04 to a maximum of US\$18,403.44 for an average 6 months of treatment for the two groups of women (102).

The total economic burden of illness for the study population (102), including direct and indirect costs, ranged from US\$840.392.79 to US\$841.059.21 for MRM and from US $\$ 244,762.04$ to US $\$ 245,428.44$ for CS (Table 4).

\section{Time adjustment and discount rate}

A general formula for discounting future cost was used. ${ }^{26}$ The minimum and maximum present values for MRM-treated women using a $5 \%$ discount rate, and five years of survival were US\$658,470.04 and US\$658,992.19, respectively. 
Table 2 Direct nonmedical and indirect costs classified by type of cost and number and percent of patients from questionnaire applied to 102 patients with breast cancer

\begin{tabular}{|c|c|c|c|}
\hline Item & Value US dollars (\$) & \# of patients & Percentage (\%) \\
\hline \multirow[t]{5}{*}{ Transportation } & $<\$ 4.80$ & 62 & 60.77 \\
\hline & $\$ 4.90-\$ 9.60$ & 31 & 30.40 \\
\hline & $\$ 9.70-\$ 14.42$ & 2 & 1.96 \\
\hline & $\$ 14.51-\$ 19.23$ & 2 & 1.96 \\
\hline & $>\$ 19.23$ & 5 & 4.91 \\
\hline \multirow[t]{3}{*}{ Time at hospital } & $<3$ hours & 4 & 3.93 \\
\hline & $4-6$ hours & 90 & 88.23 \\
\hline & $>7$ hours & 8 & 7.84 \\
\hline \multirow[t]{3}{*}{ Meals during hospital visit } & $<\$ 4.80$ & 7 & 6.87 \\
\hline & $\$ 9.70-\$ 14.42$ & 11 & 10.78 \\
\hline & None & 84 & 82.35 \\
\hline \multirow[t]{2}{*}{ Absence from work during treatment } & Yes & 15 & 14.70 \\
\hline & No & 87 & 85.30 \\
\hline \multirow[t]{5}{*}{ Loss of income } & $<\$ 96.15$ (\$US/month) & 4 & 3.93 \\
\hline & $\$ 96.13-\$ 192.30$ (\$US/month) & 9 & 8.82 \\
\hline & $\$ 192.30-\$ 288.46$ (\$US/month) & 3 & 2.94 \\
\hline & $>\$ 288.46$ (\$US/month) & 3 & 2.94 \\
\hline & None & 83 & 81.37 \\
\hline \multirow[t]{3}{*}{ Dietary changes } & $\$ 96.15$ (\$US/month) & 75 & 73.52 \\
\hline & $\$ 96.13-\$ 192.30$ (\$US/month) & 21 & 20.58 \\
\hline & $>\$ 192.30$ (\$US/month) & 6 & 5.9 \\
\hline \multirow[t]{5}{*}{ Noncovered medical expenses } & None & 82 & 80.4 \\
\hline & $<\$ 48.07$ (\$US/month) & 10 & 9.8 \\
\hline & $\$ 48.7-\$ 96.15$ (\$US/month) & 4 & 3.92 \\
\hline & $\$ 96.15-\$ 192.30$ (\$US/month) & 4 & 3.92 \\
\hline & $>\$ 192.30$ (\$US/month) & 2 & 1.96 \\
\hline \multirow[t]{5}{*}{ Other expenses related to the disease } & None & 36 & 35.30 \\
\hline & $<\$ 48.07$ (\$US/month) & 19 & 18.62 \\
\hline & $\$ 48.07-\$ 96.15$ (\$US/month) & 19 & 18.62 \\
\hline & $\$ 96.15-\$ 192.30$ (\$US/month) & 21 & 20.58 \\
\hline & $>\$ 192.30$ (\$US/month) & 7 & 6.88 \\
\hline
\end{tabular}

The minimum and maximum present values for CS-treated women using a $5 \%$ discount rate, and five years of survival were US\$191777.55 and US\$192,299.69, respectively.

\section{Discussion}

Although the present study used a small sample and a relatively short period of time, the results are consistent with information suggesting that $\mathrm{BC}$ is detected at advanced stages in Mexico. ${ }^{7}$

Most woment in the present study received MRM. In the US, in contrast, researchers report that a greater proportion of women with $\mathrm{BC}$ receive $\mathrm{CS}$ than MRM. ${ }^{27}$ Patients who received CS tended to have a higher level of education than women who received MRM. The same relationship between level of education and treatment was found by Janz and colleagues. ${ }^{27}$ Women with more education might visit the doctor more often, or might be better informed about early detection of $\mathrm{BC}$.

The majority of women in this study were not employed outside the home, unlike the US study by Janz and colleagues. $^{27}$ In Mexico, unemployment is higher among women and in general, than in the US.

In the present study, $36.27 \%$ of the women were accompanied by a son or daughter, and $30.40 \%$ by a spouse. 
Table 3 Direct nonmedical and indirect costs grouped and calculated for total sample (102 women) from responses to questionnaire and study assumptions

\begin{tabular}{ll}
\hline Item & Cost (US\$) \\
\hline Transportation & $2,942.30$ \\
Meals & 9553.84 \\
Dietary changes & $70,615.38$ \\
Noncovered medical costs & 487.50 \\
Other nonmedical costs & $5,235.57$ \\
Subtotal direct nonmedical costs & $88,834.61$ \\
Indirect costs & \\
Time at hospital (appointment or therapy) & $1312.61-1961.13$ \\
Loss of income & $16,442.30$ \\
Indirect costs subtotal & $17,737.03-18,403.44$ \\
Minimum total costs & $106,589.53$ \\
Maximum total costs & $107,238.05$ \\
\hline
\end{tabular}

The data on occupation of the accompanying person were similar to those in the study by Pandey and colleagues, which also found that the accompanying person tended to be an unemployed spouse or son or daughter. ${ }^{28}$ In the present study, $80.39 \%$ of the accompanying persons were not employed outside the home. ${ }^{28}$

The majority of the women used buses, subway or both to get from their homes to the hospital. Due to the heavy traffic in Mexico City, commuting "distances" are commonly measured in minutes and hours rather in kilometers, as they were in this study, making it impossible to draw comparisons with other studies. The time spent in hospital was 4 to 6 hours.
These times are quite high, perhaps due to staff shortages in the social security system..$^{29}$

Responses on expenses for meals and medications during hospital visits were quite varied. An average of US\$5.29 was estimated which, if considered to include the accompanying person's meal, is a reasonable amount for a lunch for two people given the cost of living in Mexico City.

The cost of dietary modifications was the highest component of nonmedical expenses (US\$70.615.38), which may mean that women diagnosed with $\mathrm{BC}$ make an extra effort to consume a balanced diet and less fat.

There should not have been any uncovered medical costs, as the social security system supposedly covers all medical expenses for beneficiaries; nevertheless, 20 women indicated that they incurred such expenses. Most women (56) reported nonmedical expenses related to their illness. These could have been cosmetic items, for example wigs or prostheses.

FEC therapy was approximately $10 \%$ more expensive than CMF therapy, and MRM surgery cost approximately $30 \%$ more than CS (US\$2106.73 and US $\$ 1428.85$ per patient respectively). The cost of medication was relatively low, as the social security system buys drugs by public tender and in bulk.

Total loss of income was estimated at US\$16,442.31. However only a small number of women were employed outside the home, a minimum monthly wage of US\$144.23 was assumed, and costs were estimated based on only a six month period. It is likely that costs were underestimated due to the limitations of the present study. Total indirect

Table 4 Direct and indirect costs of chemotherapy with FEC or CMF per patient and for six months treatment (total patients, 97)

\begin{tabular}{|c|c|c|c|c|c|}
\hline & $\begin{array}{l}\text { FEC (\$US) } \\
\text { per patient }\end{array}$ & $\begin{array}{l}\text { CMF (\$US) } \\
\text { per patient }\end{array}$ & Cost & MRM n = 82 (\$US) & $\begin{array}{l}\text { Conservative } S \\
n=15 \text { (\$US) }\end{array}$ \\
\hline Drugs & 1063.46 & 1220.38 & Direct & & \\
\hline $\begin{array}{l}\text { Clinical and laboratory } \\
\text { examinations }\end{array}$ & 57.69 & 57.69 & ${ }^{\mathrm{a} C h e m o t h e r a p y}$ & $561,069.23$ & $116,757.69$ \\
\hline Consumables & 9.61 & 9.61 & Surgery & $|72,75| .92$ & $21,432.69$ \\
\hline $\begin{array}{l}\text { Equipment } \\
\text { and infrastructure }\end{array}$ & 3.84 & 3.84 & Subtotal direct & $733,821.15$ & $138,190.38$ \\
\hline Personnel & 5.76 & 5.76 & 'Subtotal nonmedical & $88,834.61$ & \\
\hline Subtotal per cycle & 1140.38 & 1297.30 & 'Subtotal indirect & $17,737.03-18,403.44$ & \\
\hline \multirow{2}{*}{$\begin{array}{l}\text { Total cost for } 6 \\
\text { chemotherapy } \\
\text { cycles/patient }\end{array}$} & 6842.30 & 7783.84 & $\begin{array}{l}\text { MRM total minimum } \\
\text { and maximum }\end{array}$ & $\begin{array}{l}840,392.80 \text { and } \\
841,059.21\end{array}$ & \\
\hline & & & $\begin{array}{l}\text { CS total minimum } \\
\text { and maximum }\end{array}$ & $244,762.03-245,428.44$ & \\
\hline
\end{tabular}

Notes: a Cost per patient was multiplied by 6 (number of complete treatment cycles) and by the number of patients receiving FEC (80.4\%) or CMF (I4.7\%) chemotherapy; ${ }^{b}$ Nonmedical and indirect costs were calculated from the questionnaire responses for all women with BC (102), not by type of surgery.

Abbreviations: CMF, cyclophosphamide, methotrexate, fluorouracil; CS, conservative surgery; FEC, fluorouracil, epirubicin, cyclophosphamide; MRM, modified radical mastectomy. 
costs were US\$17.737.03, including the cost of time spent at the hospital. In another Mexican study of a different chronic disease, indirect costs were much higher than IMSS direct costs. ${ }^{14}$

We can conclude from the results of this study that current social security practice should be modified to enable early BC detection and decrease the direct and indirect costs associated with the disease. The present study makes a contribution to information that can be used to improve public health policy and improve programs for breast self-examination, both of which can aid early detection of BC.

\section{Limitations}

The number of patients was relatively small. The microcosting process has inherent limitations, as items could be either omitted or overestimated. The questionnaire had methodological limitations and limitations of scope. The results apply only to the sample and cannot be generalized to the entire Mexican or social security population. Further studies of the BC burden with greater numbers of patients are required.

\section{Conclusions}

The total economic disease burden in the study population was greater for women who received MRM than those who received CS. The direct costs of MRM are higher. Women with BC at stage I had higher levels of education. The majority of women in the present study were of reproductive age. In spite of the small size of the sample population, the finding that BC is detected at advanced stages III and IV in Mexico was corroborated.

\section{Disclosure}

The authors report no conflicts of interest in this work.

\section{References}

1. McPherson KM, Steel CM, Dixon JM. ABC of breast diseases. Breast cancer - epidemiology, risk factors, and genetics. BMJ. 2000;321:624-628.

2. Veronesi U, Boyle P, Goldhirsch A, Orecchia R, Viale G. Breast cancer. Lancet. 2005;365:1727-1741.

3. Lindley C, Michaud LB. Breast cancer. In: Dipiro TJ, Talbert RL, Yee GC, Matzke GR, Wells BG, Posey LM, editors. Pharmacotherapy. 6th ed. New York, NY: McGraw Hill; 2005. p. 2329-2364.

4. Secretaría de Salud. Situación Actual del Cáncer de Mama en México. Cited Jan 10, 2008. Available at http://www.generoysaludreproductiva. gob.mx/.

5. Instituto Nacional de Estadística. Geografía e Informática (INEGI). 2004. Cited Jan 10, 2008. Available at http://www.inegi.gob.mx/.
6. La salud y el sistema de atención. 2006. Cited Jul 20, 2008. Available at http://www.salud.gob.mx/.

7. Secretaria de salud 2002. Programa de acción: Cáncer de mama. Second edition, Mexico DF, Mexico. Cited Jul 20, 2008. Available at http//www.salud.gob.mx/.

8. Brenner $H$. Long-term survival rates of cancer patients achieved by the end of the 20th century: a period analysis. Lancet. 2002;360:1131-1135.

9. Chabner BA, Ryan DP, Paz-Ares L, Garcia-Carbonero R, Calebresi P. Antineoplastic agents. In: Hardman JY, Limbird LF editors. Goodman and Gilman's The Pharmacological Basics of Therapeutics. 10th ed. New York: McGraw-Hill; 2000. p. 1389-1460.

10. Butler A, Hoffmann RG, Kneusel RT, Schapira MM. Relation between appropriateness of primary therapy for early-stage breast carcinoma and increased used of breast-conserving surgery. Lancet. 2000;356:1148-1153.

11. Koopmanschap MA. Cost of illness studies. Useful for health policy? Pharmacoeconomics. 1998;14:143-148.

12. Legorreta AP, Brooks RJ, Leibowitz AN, Solin LJ. Cost of breast caner treatment. A 4-year longitudinal study. Arch Intern Med. 1996;156:2197-2201.

13. Lindfors KK, McGahan MC, Rosenquist CJ, Hurlock GS. Computeraided detection of breast cancer: A cost-effectiveness study. Radiology. 2006;239:710-717.

14. Arredondo A, Zuñiga A. Economic consequences of epidemiological changes in diabetes in middle-income countries. Diabetes Care. 2004;27:104-109.

15. Molinier L, Combescure C, Chouîd C, et al. Cost of lung cancer. A methodological review. Pharmacoeconomics. 2006;24:651-659.

16. Byford S, Torgerson DJ, Raftery J. Cost of illness studies. BMJ. 2000;320:1335.

17. Kiivet RA, Kaur I, Lang A, Aaviksoo A, Nirk L. Costs of asthma treatment in Estonia. Eur J Public Health. 2001;11:89-92.

18. Wong JB. Hepatitis C. Cost of illness and considerations for the economic evaluation of antiviral therapies. Pharmacoeconomics. 2006;24:661-672.

19. Begley CE, Annegers JF, Swann AC, et al. The lifetime cost of bipolar disorder in the US. An estimate for new cases in 1998. Pharmacoeconomics. 2001;19(5 pt 1):483-495.

20. Bloom BS, Bruno DJ, Maman DY, Jayadevappa R. Usefulness of US cost-of-illness studies in healthcare decision making. Pharmacoeconomics. 2001;19:207-213.

21. Shiell A, Gerard K, Donaldson C. Cost of illness studies: an aid to decision-making? Health Policy. 1987;8:317-323.

22. Rice DP. Cost of illness studies: What is good about them? Inj Prev. 2000;6:177-179.

23. Goetzel RZ, Long SR, Ozminkowski RJ, Hawkins K, Wang S, Lynch W. Health, absence, disability, and presenteeism cost estimates of certain physical and mental health conditions affecting US employers. J Occup Environ Med. 2004;46:398-412.

24. Gold MR, Siegel JE, Russell LB, Weinstein MC, editors. Cost-Effectiveness in Health and Medicine. New York: Oxford University Press; 1996.

25. Instituto Mexicano del Seguro Social. Portal de Transparencia. Cited Jun 15, 2008. Available from http://transparencia.imss.gob.mx/.

26. Muening P. Designing and conducting cost-effectiveness analyses in medicine and health care. Kamran Khan, editor. San Francisco, CA: Jossey-Bass, A Wiley Company; 2002. p. 150-151.

27. Janz NK, Mujahid M, Lantz PM, et al. Population based study of the relationship of treatment and sociodemographics on quality of life for early breast cancer. Qual Life Res. 2005;14:1467-1479.

28. Pandey M, Thomas BC, SreeRekha P, et al. Quality of life determinants in women with breast cancer undergoing treatment with curative intent. World J Surg Oncol. 2005;3:63-70.

29. Kravzov-Jinich J. Altagracia-Martínez M. Human resources in pharmacy and health in Mexico. Int Pharm J. 2006;20:7-13. 
